\title{
KNOWLEDGE MANAGEMENT FRAMEWORK FOR INTEGRATING BIOMEDICINE INTO THE NEW PRODUCT DEVELOPMENT
}

\author{
Jesus-Manuel Barragan-Ferrer, ${ }^{1,4}$, Diana Barragan-Ferrer¹, Rene Lopez-Flores ${ }^{2}$, \\ Guillermo Cortes-Robles ${ }^{3}$, Ingrida Viliušiené ${ }^{1}$, Jolita Kirvaitiené ${ }^{1}$ \\ ${ }^{1}$ Faculty of Medicine, University of Applied Sciences, Kaunas, Lithuania, \\ ${ }^{2}$ Facultad de Ingeniería Química, Universidad Autónoma de Yucatán, Periférico Norte Km 33.5, \\ 97203 Mérida, Yucatán, México, ${ }^{3}$ Division of Graduate Studies and Research, Orizaba Institute of \\ Technology, Av. Oriente 9, No. 852, Col. E. Zapata, CP 94320 Orizaba, Veracruz, Mexico, \\ ${ }^{4}$ Department of Food Science and Technology, Faculty of Chemical Technology, Kaunas University \\ of Technology, Kaunas, Lithuania
}

Key words: biomedicine, knowledge management, new product development, innovation.

\begin{abstract}
Summary
In this article, a knowledge management framework is proposed as a strategy to improve the new product development (NPD) process through the integration and application of scientific knowledge and experience of biomedicine. The framework provides efficient management of the knowledge developed through the NPD activities, it creates a collaborative environment to promote innovation, and it provides the mechanism to integrate the knowledge of biomedicine to increase interdisciplinary scientific knowledge to create new opportunities for the development of innovative products.
\end{abstract}

\section{Introduction}

Confronted with highly competitive markets characterized by faster and uncertain changes in the needs of customers, the industry requires that the new product development (NPD) process has the capacity to innovate constantly to design products and services that better meet theses shifting needs. Traditionally, the NPD process is mainly addressed by engineering and management approaches. However, since there is an increase in complexity of new products, it is necessary the access of knowledge from other fields.

Following this trend, biomedicine is one option to provide new scientific knowledge and experiences that are difficult to acquire in engineering science. Successful collaboration between engineering and biomedicine a have long record of in the development of medical technologies, but biomedicine has remained on the periphery in the NPD. Nevertheless, biomedicine has much to contribute to NPD. Large amount of knowledge, scientific effects and phenomena widely used in biomedicine could contribute to the development of new products and technologies. Take, for example, the antimicrobial properties of silver and gold ions that have been used for medical purposes for many years to prevent infection. More recently, this property has been applied to consumer products to kill bacteria [1].

The aim of this article is to propose a framework that would enable collaborative innovation and knowledge management during the NPD process to integrate scientific knowledge and experiences of biomedicine to increase interdisciplinary scientific knowledge in developing new products.

\section{Sources and methods}

A literature review was undertaken to identify the key components that are required for developing a knowledge management framework.

New product develop process. The new product development (NPD) process is focused on the creation of new business opportunities through the development of better products to meet the market demands and others social needs. In general, the NPD process (Fig. 1) involves the following phases [2]: 1) Discovery: 2) Definition 3) Design, 4) Development, 5) Delivery. This process begins with the identification of opportunity of a problem to solve which is defined in detail in the next phase. Then, the design phase involves the search for ideas to generate concepts. The concepts with the highest potential for becoming a product are 
developed to create working models which are then evaluated. Finally, the delivery phase involves the positioning and launch of the new product.

To ensure a competitive advantage, the NPD should be a dynamic and continuous process of transforming ideas into innovative products [3]. Thus, innovation plays a key role in this process. However, the creation of an innovative product is always a new challenge due to that it involves a complex coordination of social, political, managerial, commercial, religious, biological, and medical factors. The reduction in this complexity of innovation has a large dependence on the availability of multidisciplinary knowledge of science and engineering [4]. Therefore, it is necessary the ability to generate, share and apply creatively the knowledge from multiple sources through collaboration to generate new ideas which can be translated into commercial and viable solutions [5]. Hence, knowledge and a collaboration are fundamental factors to innovate that lay at the core of NPD processes [6].

Now, organizations are becoming more concerned about the importance of both factors. As a result, knowledge management, on the one hand, has emerged as an alternative to capture, manage and preserve the existing internal and external knowledge in an organization to be used to innovate faster and more successfully [4]. On the other hand, the collaborative innovation emerges as an alternative for sharing and generating highly valuable knowledge by a multidisciplinary collaboration to stimulate the innovation process [7]. Both elements, which are discussed below in more detail, could be integrated as supports for the NPD to have the ability to capitalize interdisciplinary knowledge to encourage the development of future innovations.

Collaborative innovation. Collaborative innovation is the process whereby the firm creates and integrates knowledge and expertise from internal and external actors through collaborative work to accelerate the innovation process [8]. The collaborative innovation is based on the collective intelligence paradigm in which it is possible to

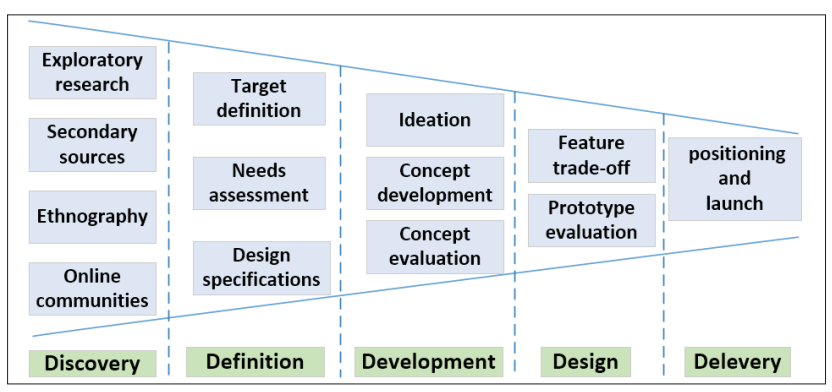

Fig. 1 The new product development process. obtain more competence, resources, or information to solve problems through the intelligence of groups than individuals working in isolation [9]. Recently, as new information and communication technologies supporting collaboration have become available and the necessity of interconnections among different sciences to solve complex problems, the collective intelligence is used in the collective innovation as a distributed architecture for collaboration to facilitate the participation of different actors in the design of new products or in the problem-solving process [10].

This way of collaboration represents a paradigm shift in the innovation process that is attracting the attention from researchers, academics, and business communities to create multidisciplinary workgroup networks to develop innovative products. The advantage is the possibility to integrate external and external knowledge to stimulate innovation in different phases of new product development. However, there is still a need for a mechanism to identify, formalize and store the knowledge used during this process to be used for creating future innovations. As the next section presents, Knowledge management has emerged as an approach to solving this problem.

Knowledge management. Knowledge has always been at the core of economic development and social progress [11]. The production and integration of new knowledge combined with the capacity of learning quickly to solve problems are vital to adapt to the changes in the business environment and to innovate. Thus, organizations are seeking ways to acquire, create, develop, share, transfer and apply knowledge to create sustainable competitive advantage. Knowledge management has emerged as a solution to these issues.

Knowledge management can be described as the process to formalize and manage (create, transform, transmit and incorporate) internal and external knowledge to make them available in order to be used effectively and efficiently to generate ideas, practices, process, products or services in a successful manner in response to market demands and others social needs. Knowledge can be either explicit or tacit and includes facts, opinions, ideas, theories, principles, models, experience, know-how, values, contextual information, expert insight, and intuition [12]. The benefices of a knowledge management approach include the creation of an environment to facilitate the collaboration, knowledge sharing, and the creation of a continuous learning environment which are key elements of collaborative innovation [4]. In addition, Knowledge management could be an important support to locate and identify essential knowledge in the different domains of science in order to increase interdisciplinary scientific knowledge to the NPD process. 
The knowledge management process used to manage the different types of knowledge involves the following steps [13]:

- Knowledge assessment: in this step, it is necessary to identify and assess the crucial knowledge from various sources and from various experiences to be preserved.

- Knowledge generation: in this step new knowledge is created through collaboration, research or combination of knowledge and experiences.

- Knowledge capture: This step consists in the selection and storage of valuable knowledge.

- Knowledge synthesis: in this step, knowledge preserved is generalized in guidelines or best practices are available to be used.

- Knowledge sharing: in this step the generalized knowledge is transferred through various communication mechanisms such as discussion forums, online publications, communities of practice, collaboration networks to create new knowledge and solve future problems.

The integration knowledge management could be a support to locate and identify essential knowledge of biomedicine that can be used in the NPD process. But there are still two principal barriers to the integration of biomedicine in this process: the difficulty of merging the biomedical scientific knowledge into the engineering knowledge which is the most often used in the NPD. Secondly, most of the knowledge used during the development of new products exists tacitly and therefore it is necessary a mechanism that capitalizes this type of knowledge [6]. Thus, the next subsection describes the mechanism to deal with this first issue. For the second issue, our framework looks into this problem and proposes an appropriate solution.

Integrating the knowledge of biomedicine. As is well known, the introduction of new scientific knowledge or the use of knowledge in another context or domain leads to proposing new creative ideas. This is the case for several scientific effects or phenomena that had been identified across the scientific domains and been applied in the development of new products.

In our case, we are interested in integrating the biomedical scientific knowledge into the engineering knowledge that is used in the NPD. Thus, the methods and techniques of engineering design could offer a unique opportunity to formalize, model, visualize and transfer the knowledge of biomedicine into the common vocabulary. In particular, the functional representation used by Pahl \& Beitz [14] could make possible this formalization.

Functional representation process

The first step in this process is the identification of valuable knowledge of biomedicine. Knowledge acquires value when it solves a problem, it provides a useful action or it creates an improvement (in a process, product or service). In the next step, this valuable knowledge is translated into a common vocabulary for engineering using functions. A function is defined in the form of verb + subject that expresses in abstract form the desired change in an object (substance or energy) or its properties (Table 1). Thus, using this functional representation, the common biomedical knowledge can be redefined as follows: the name to define the knowledge, the type of knowledge (principle, practice, method, phenomena or effect), its description, the function that it carries out, the result of this function as desired action/improvement that it provides and/or the problems that it solves, the necessary conditions of its existence and those who possess this knowledge (if it were the case). Finally, this information is used to create a new knowledge to be stored for future use. For example, a well-known effect in biomedicine is the antibacterial effect of silver, it can be defined with the function "reduce the amount of substance (bacteria)" that result in the prevention of infection. Application of silver: as a substitute of inorganic oxides and organic material biocide, for water disinfection, nanosilver coatings to prevent the formation of bacteria are applied to portable communication apparatus, food packages, refrigerators, washing machines, clothing, and personal hygiene products (Table 1).

In addition, this functional modeling can be used as a way of facilitating the communication of the problems of biomedicine to engineers. A problem can be defined as

Table 1. General functions used to describe knowledge, principles, experiences, scientific effects or phenomena of Biomedicine.

\begin{tabular}{|l|l|}
\hline Function & \multicolumn{1}{|c|}{ Description } \\
\hline Transform & $\begin{array}{l}\text { Transformation of energy or substance (genera- } \\
\text { tion/elimination) }\end{array}$ \\
\hline Reduce & $\begin{array}{l}\text { Reduction in the amount of energy, substance or } \\
\text { the properties of a substance }\end{array}$ \\
\hline Control & $\begin{array}{l}\text { Regulate the state of substance or the properties } \\
\text { of a substance }\end{array}$ \\
\hline Increase & $\begin{array}{l}\text { Increase the amount of energy, substance or the } \\
\text { properties of a substance }\end{array}$ \\
\hline Join & Join energy and substance \\
\hline Separate & Separate energy and substance \\
\hline Transport & Transport of energy or substance over a distance \\
\hline Store & $\begin{array}{l}\text { Accumulation of energy or substance over the } \\
\text { time }\end{array}$ \\
\hline Dissipate & Dissipation of energy or substance over the time \\
\hline Measure & $\begin{array}{l}\text { Measure the amount of energy/substance or the } \\
\text { properties of a substance }\end{array}$ \\
\hline
\end{tabular}


an action performed by a product or process. This action can be expressed as adequate, but requires improvement, harmful that requires its elimination, excessive or insufficient that requires its enhancement, and absent that requires its introduction. Then, the Root Conflict Analysis [15], another engineering tool, can be used to complement the description of this problematic situation. Using both descriptions, a common vocabulary can be created to define the precise meaning of concepts and their relationships in a biomedical problematic situation and then the problem can be easily interpreted for engineers.

Another way to incorporate the knowledge of biomedicine into the NPD is through the inclusion of experts in the collaborative process. Here, the information of experts interested in participating is included in a collaborative network to take an active part in the NPD.

Having defined the mechanism to translate the knowledge of biomedicine into a functional language, it is necessary integrates this knowledge into the NPD. The framework described in the next section makes possible this integration.

\section{Knowledge Management framework}

After analyzing the principal elements of knowledge management and NPD process as well as the description of formalism for integrating the knowledge of biomedicine into the NPD process, we propose a Knowledge management framework (Fig. 2) in this section to put together all these components. The core of the framework is composed of four principal parts, described below:

1) The NPD process: It describes the phases of NPD and its activities. Each activity uses and produces knowledge, generates problems to be solved and requires actors

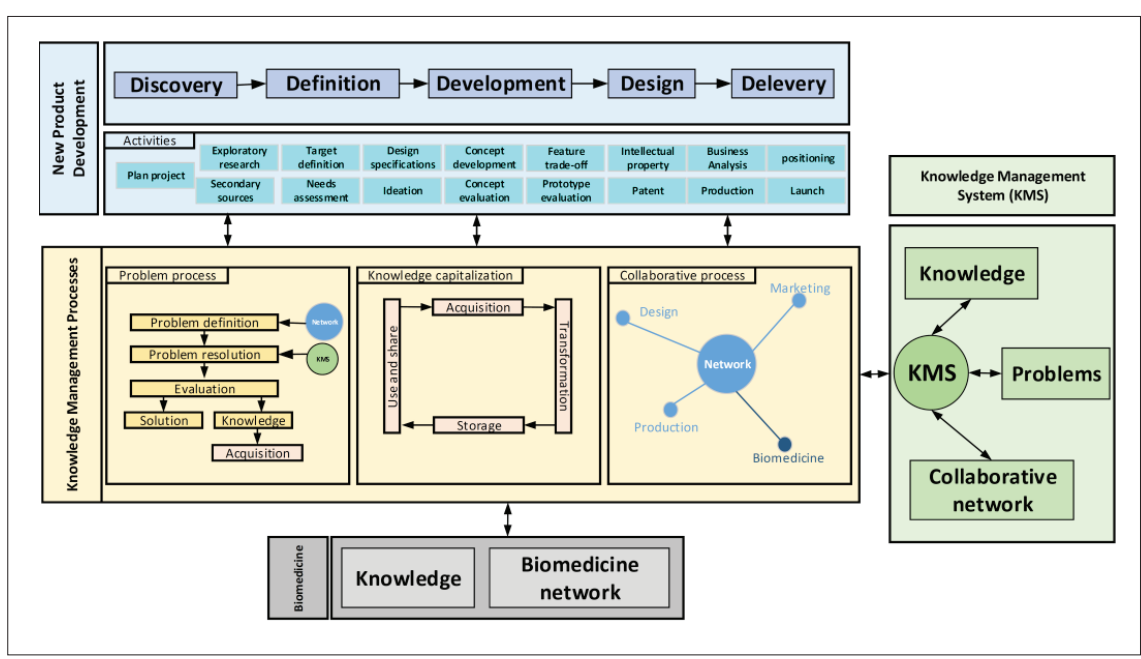

Fig. 2 the Knowledge management framework. to functioning effectively.

2) The knowledge management processes: this part describes the different processes in which the knowledge (tacit and explicit) is used in each activity of NPD. These processes are:

a) The problem-solving process: This process tries to solve problems that arise during each activity in the NPD. Also, it aims to capture the tacit and explicit knowledge used during the resolution process in order to be capitalized for future use. This process begins with the network of actors that collaborate to define the problem. The problem can be defined as a desired function to provide or an action to be performed (see section 2.4). Once the problem defined, in next step the actors try to solve the problem using the knowledge and problems that have been faced and resolved in the past using the knowledge management system (KMS). In the last step, the final solution, if it exists, is implemented and incorporated in the KMS to be reused in the future. Also, the knowledge, problems and experiences used and created in this process are capitalized (stored in the KMS).

b) Knowledge capitalization: this process is based on the knowledge management process described in section 2.3 , and it aims is to capitalize the knowledge used in the different steps of NPD or in the resolution of problems. It also capitalizes the external knowledge of different domains of science, in our case the knowledge of biomedicine, in explicit form to be used in the future. Here, knowledge is described as any method, principle, effect or phenomena that can serve as a model or rule. The process starts with the discovery, collection, analysis and identification of knowledge from the activities and external sources. In the second step, this new knowledge, that in some cases can be combined with existing knowledge stored in the knowledge management system, is transformed into some form that we can able to apply. In the next step, this new knowledge is organized in such way that is stored and easily accessible. In the last step, the new knowledge can be used in the NPD and shared with the collaborative network using, for example, case studies, best practices, guidelines, manuals, publications, meeting or other communication ways.

c) Collaborative process: a collaborative network is created with the aim of creating collaborative environments where a research com- 


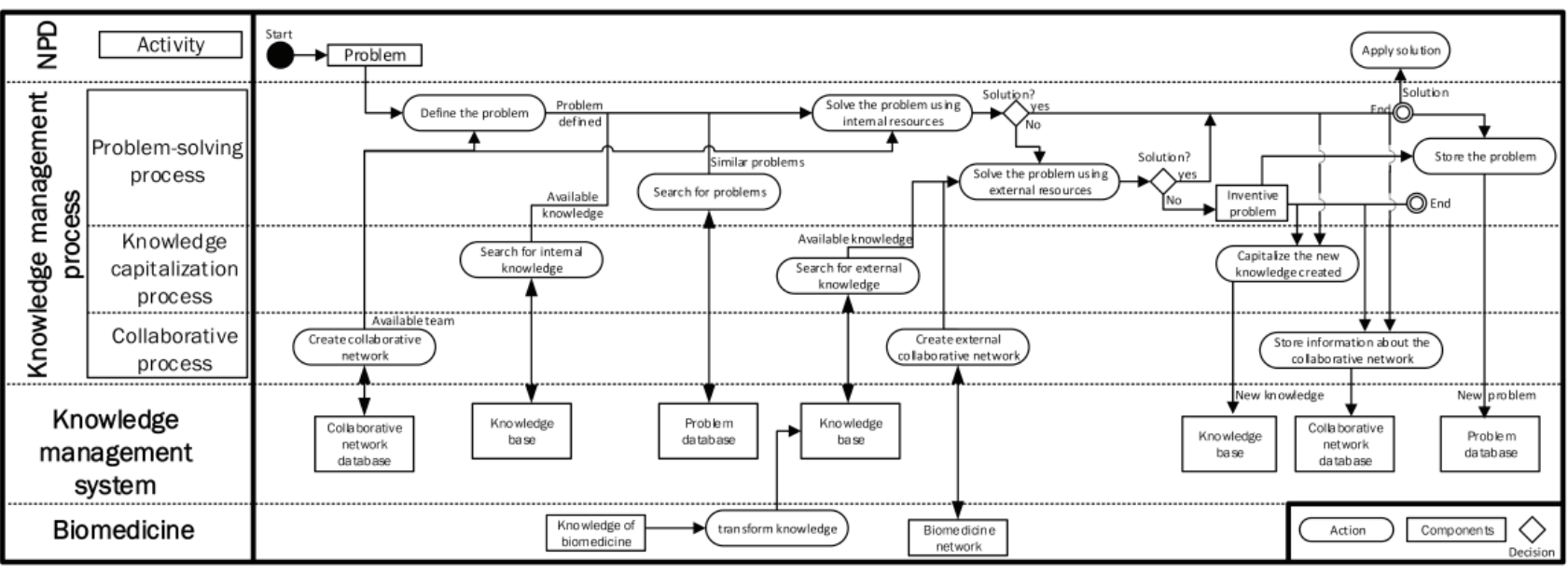

Fig. 3 Example of problem-solving process using the knowledge management framework.

munity (called actors) represents, shares and produces new knowledge. The participation of these actors depends on the knowledge needed to execute the activities in the NPD or during the resolution of problems. The actors can be internal, for example, different departments in the organization or an external source, for example, a biomedicine research team.

3) The knowledge management system: This system is used to organize and make readily accessible the knowledge identified in the knowledge management processes. Also, this system allows the interaction among the parts of the framework. It contains three main elements:

a) Problem database: In this element is stored the problems that have been previously solved along with their associated solution methods that can serve as a model for future problems. Also, additional information is considered such as the result that describes the success or failure obtained by applying this solution, the date, localization and the actors that take part in the resolution and their recommendation to implement the solution.

b) Knowledge database: in this element the knowledge that has been used and created in the NPD and in the problem-solving process is stored for future use. Knowledge has the following main features: description, type (method, practice, principle, effect, or phenomena), its function, the problem it solves, the desired action that it provides, and those who possess this knowledge.

c) Collaborative network: In the production of knowledge, the actors play a significant role. Thus, this element is a database of actors that have participated in the knowledge management processes and the information about them such as personal data, skills, topics of interest, research group to which he/she belongs is captured. This will allow searching for information about who has specific knowledge and skills. It also identifies the collaborators in the organization that have participated in different activities in the NPD as well as the external actor with the knowledge necessary to participate in the NPD.

The knowledge of biomedicine. The aim of this part of the framework is to incorporate the knowledge of biomedicine, considered as an external source of knowledge, into the NPD. This knowledge can be stored in the knowledge management system using the formalism described in the section 2.4 or can also be found in tacit form in a biomedicine collaborative network and used in the problem-solving process.

\section{Framework implementation}

Fig. 3 shows the process for solving a problem using the knowledge management framework. The process starts identifying an important problem during the NPD process. In the next step, a collaborative team is created to define the problem. Next, to solve the problem, internal resources are used (collaborative team, available knowledge and similar problems). If a solution is found, the solution is applied. Otherwise, we need to search for external knowledge. Here, it is necessary to create a collaborative team with the biomedicine research group, and to use the knowledge of biomedicine (previously adapted to NPD). If no solution can be found with this external knowledge, we are dealing with an inventive problem and then additional methods and tools are needed. In all of these cases, the information of the problem and the collaborative team, as well as the knowledge created during the problem-solving process is stored in the knowledge management system. 


\section{Results}

As a result of our research, a knowledge management framework is presented in this article. This framework provides the mechanism to integrate the knowledge of biomedicine, such as principles, experiences, scientific effect and phenomena that are difficult to acquire in engineering science that can be very useful in the NPD process. Also, from our perspective, the knowledge can be created and disseminated trough the problem solving process, the collaborative network, and the Knowledge capitalization process. However without the possibility of storing this knowledge, it cannot be reused. That is the reason why we include the knowledge management system (KMS) in our framework.

Moreover, among the most important advantages of this framework are: 1) It creates the necessary conditions to assist the innovation process through its capacity to identify, preserve, reuse and disseminate knowledge and experiences inside and outside the organization. 2) It promotes the collaboration of external and internal groups of research to work together in the resolution of multidisciplinary problems. 3) It proposes the mechanisms to facilitate the communication of problems between biomedicine and engineering researchers. 4) The problem-solving process could save time, resources and money by preventing the repetition of similar problems that have already been solved.

However, during the development of the framework, we found also that it has some limitations: the success of collaborative participation depends on the selection of appropriated participants. The existence of psychological barriers in organizations and collaborators to share and store in a system their sensitive knowledge that they have accumulated over several years. The implementation of KM system takes some time to be fully operational, but organizations are reluctant to invest time and money into a novel technology that benefits will be obtained in the medium-long term. Another limitation is when an inventive problem appears, that is, when a new problem appears, similar problems to be adapted cannot be found in the problem base or the knowledge of participants in the collaborative network is limited to try to solve it. In this case, there is an evident need for methods and tools to deal with this type of inventive problems.

\section{Conclusion}

1. The framework: given the importance of knowledge in the NPD, in this article, we have focused on the development of a knowledge management framework applied to NPD. This framework provides the elements and mechanisms to integrate the NPD process, the knowledge management process, a knowledge management system, and biomedicine into a cohesive process to acquire new knowledge and manage the existing ones to generate new ideas and to solve problems during the development of new products and processes. Thus, we believe that this framework can offer a great support for the improvement of the NPD.

2. Biomedice in the NPD: by showing how the framework provides the mechanism to capitalize the knowledge of biomedical science, this framework opens up new opportunities to apply biomedicine in the development of innovative products or provides new opportunities for research in diverse areas. For example, in the process of knowledge capitalization on patents, it was found the effect of polymers which can dissolve in the organism once a particular $\mathrm{pH}$ value is attained (US Patent US5118528). This effect that has been used for medical purposes for a very long time could provide new applications in other engineering domains that must be explored.

3. Future work: the most interesting of this framework is that it can be used to develop a collaborative platform. Thus, it is expected to integrate the Web 2.0 collaborative technologies and the framework presented in this work to create an open and collaborative innovation platform for biomedicine to facilitate the interdisciplinary collaboration of engineering, biomedicine, and other domains of science to develop new products.

\section{Acknowledgements}

The National Council of Science and Technology (CONACYT), the Public Education Secretary (SEP) through PRODEP sponsored, and The Tecnologico Nacional de Mexico supported this work. Additionally, the ROPRIN working group (Network of Optimization in Industrial Processes) offered a valuable support.

\section{References}

1. Blanton TN, Scheible JJ, Munro G, et al., inventors. Antibacterial and antifungal protection for toner image. United States patent US 20130071143 A1. 2011 Mar 21.

2. Katz G. Rethinking the product development funnel. Visions. 2011;35(2).

3. Aleixo GG, Tenera AB. New product development process on high-tech innovation life cycle. World Acad Sci Eng Technol 2009;58:794-800.

4. Plessis M Du. The role of knowledge management in innovation. J Knowl Manag. 2007;11(4):20-29. https://doi.org/10.1108/13673270710762684

5. OECD. Biomedicine and health innovation: Synthesis Report 2010.

6. Pitt M, Macvaugh J. Knowledge management for new product development. J Knowl Manag 2008;12(4):101-116.

https://doi.org/10.1108/13673270810884282

7. Cavusgil ST, Calantone RJ, Zhao Y. Tacit knowledge transfer and 
firm innovation capability. J Bus Ind Mark 2003;18(1):6-21. https://doi.org/10.1108/08858620310458615

8. Ketchen D, Ireland R, Snow C. Strategic entrepreneurship, collaborative innovation, and wealth creation. Strateg Entrep J 2007; (1):371-385.

https://doi.org/10.1002/sej.20

9. Gregg DG. Designing for collective intelligence. Commun ACM 2010; 53(4):134.

https://doi.org/10.1145/1721654.1721691

10. Flores R, Belaud J, Le Lann J, Negny S. Using the collective intelligence for inventive problem solving: a contribution for open computer aided innovation. xpert Syst with Appl. 2015; 42(23):9340-9352.

https://doi.org/10.1016/j.eswa.2015.08.024

11. Rooney D, Hearn G, Ninan A. Handbook on the knowledge economy. Handb Knowl Econ Ed 2005:290. https://doi.org/10.4337/9781845426842

12. Popadiuk S, Choo CW. Innovation and knowledge creation: How are these concepts related? Int J Inf Manage 2006;26(4):302-312.

https://doi.org/10.1016/j.ijinfomgt.2006.03.011

13. Ohkubo S, Sullivan TM, Harlan SV, Timmons BT, Strachan M. Guide to monitoring and evaluating knowledge management in global health programs. 2013.
14. Pahl G, Beitz W, Feldhusen J, Grote K-H. Engineering design: a systematic approach. Springer 2007;(2):617.

15. Souchkov V. Root conflict analysis $(\mathrm{RCA}+)$ : structured problems and contradictions mapping. In: proceedings of TRIZ future conference, Graz, Austria. 2005.

\section{ŽINIŲ VALDYMO SISTEMA SKIRTA INTEGRUOTI} BIOMEDICINOS SRITI

\section{KURIANT NAUJUS PRODUKTUS}

\section{J. M. Barragan-Ferrer, D. Barragan-Ferrer, R. Lopez-Flores,} G. Cortes-Robles, I. Viliušienė, J. Kirvaitienė

Raktažodžiai: biomedicina, žinių valdymas, naujų produktų kūrimas, inovacijos.

Santrauka

Šiame straipsnyje pateikiama žinių valdymo sistema kaip strategija, siekianti pagerinti naujų produktų kūrimo (NPD) procesą taikant biomedicinos srities mokslo žinias. Ši sistema padeda efektyviai valdyti žinias ir jas panaudoti naujų produktų kūrimui bei suformuoti mechanizmą, kurio pagalba integruojamos biomedicininès ir tarpdisciplininių dalykų žinios, suteikiančios galimybę sukurti naujus novatoriškus produktus.

Correspondence to: diana.barragan.ferrer@go.kauko.lt

Gauta 2016-11-14 